\title{
Assessment of targeted yield of the wheat through INM based on soil test crop performance (STCR)
}

MANOJ KUMAR SINGH, JITENDRASINGH AND PAWAN SIROTHIA

Received : 16.10.2017; Revised : 21.11.2017; Accepted : 29.11 .2017

MEMBERS OF RESEARCH FORUM:

Corresponding author : MANOJ KUMAR SINGH, Holy

Cross Krishi Vigyan Kendra, HAZARIBAG (JHARKHAND) INDIA

Email: manojlohrapur@gmail.com

Co-authors :

JITENDRA SINGH, Krishi Vigyan Kendra, INDORE (M.P.) INDIA

PAWAN SIROTHIA, M.G.C.G. Vishvavidyalay Chitrakoot, SATNA (M.P.) INDIA

\section{Summary}

India recorded impressive achievement in agriculture since the onset of green revolution which enabled the country to overcome wide spread hunger, achieve self-sufficiency in food and bring economic transformation. The situation, however started turning adverse, with slow down in the growth rate of output due to decline in soil fertility. This situation can only improve with the help of integrated nutrient management (INM) based on soil test crop response (STCR) nutrient application in the soil, according to the soil formula so that we can get targeted yield of the crop and sustain the soil fertility. Holy Cross Krishi Vigyan Kendra has conducted experiments to assess the STCR to achieve target yield of wheat. On Farm Trials (OFT) were conducted on the farmers fields in 10 different locations. The soil is sandy loam in midland situation the soil reaction was acidic and low or medium in organic matter. The soil samples for soil fertility status were analyzed at initial and final stage of the crop with other agronomic parameters. The source of the technology was Jawaharlal Krishi Vishwavidyalay, Jabalpur (M.P). During Rabi season of 2011 - 12 and 2012-13 studies were conducted to find out the doses of fertilizer to obtain targeted yield economically. Three technical options adopted for the experimentation were: Farmers practice $-35 \mathrm{q} / \mathrm{ha}$, fertilizers dose were $80 \mathrm{~kg}$, nitrogen, $60 \mathrm{~kg}$ phosphorus and $20 \mathrm{~kg}$ potash). Technical option 1 - targeted yield $40 \mathrm{q} / \mathrm{ha}$, fertilizers dose by STCR based were 90:55:69 and Technical option 2 - targeted yield $42 \mathrm{q} / \mathrm{ha}$, fertilizer dose by STCR based were 107:63:75. The technical option 1 was the best to adopt as per the assessment and refinement.

Key words : Nutrient management, Soil test crop performance (STCR), Yield, Wheat

How to cite this article : Singh, Manoj Kumar, Singh, Jitendra and Sirothia, Pawan (2017). Assessment of targeted yield of the wheat through INM based on soil test crop performance (STCR) . Asian J. Soil Sci., 12 (2) : 346-348 : DOI : 10.15740/HAS/AJSS/12.2/346-348. 